\title{
The Explorations and Implications of EFL Class Activity Design via Smartphone Applications
}

\author{
Yiching Chen
}

\begin{abstract}
As a number of studies show the potential of mobile-assisted language learning (MALL) in the classroom, most have been conducted by using smartphone applications as a platform to freely communicate or share information among peers. However, other than functioning as social support media in the classroom, smartphone applications might be able to play a more multi-functional role. With this attempt, the researcher aims to explore two domains. One is to challenge the diversity of class activity design and its feasibility while integrating smartphone applications such as LINE into a class agenda. Learning English as a foreign language (EFL) was main subject of the experiment. Fifteen different activities designed by the researcher were implemented to offer EFL learners more opportunities to strengthen their language skills. Investigations of the effects were carried out by questionnaires and interviews. The other research goal is to inspect the educational implications emerging from this mobile application pedagogy. Roles of smartphone applications, particularly in big-sized classes, and their impacts on the teacher and learners are considered. Furthermore, the elements underpinning a satisfying MALL learning process are discussed and a design model for MALL classroom is also initiated.
\end{abstract}

Index Terms-Class activity design, design models, English as a foreign language (EFL), mobile-assisted language learning (MALL), smartphone applications.

\section{INTRODUCTION}

Mobile devices integrated with conventional curriculum have been gaining increasing attention in recent years [1]-[11]. By using existing devices such as smartphones, classes can be wired up with zero investment in new hardware. However, this trend has been impacting and challenging traditional ways of learning and teaching. It seems that we educators are put out there on the front of the cutting edge with no previous educational theories to draw upon. The question is, how can we integrate social media such as smartphone applications into our teaching arena and make the most out of them? Some know-how information is needed. For example, what are the suitable types of class activities for Mobile-Assisted Language Learning (MALL)? What aspects should be considered when designing MALL activities? What are the pedagogical implications elicited from them? As an educator facing a "digital native" generation, these questions seem to be presently prominent.

Bearing these things in mind, the objectives of this study are twofold. One is to explore the diversity of class activity design and its feasibility. A learning English as a foreign

Manuscript received December 30, 2016; revised February 19, 2017.

Yiching Chen is with Takming University of Science and Technology, Taipei, Taiwan (e-mail: ycac@takming.edu.tw). language (EFL) class was the main subject of the experiment. The smartphone application LINE, Taiwan's largest social network, was blended into the class agenda. Fifteen different activities designed by the researcher were implemented in the study. Investigations on the effects were carried out by questionnaires and interviews. The other research goal is to inspect the educational implications emerging from this mobile application pedagogy. Furthermore, the elements underpinning a satisfying MALL learning experience are discussed and a design model for a MALL class is also developed.

\section{THE STUDY}

\section{A. Participants}

The participants were studying English as a foreign language (EFL) as their majors in a Taiwanese university located in Taipei. They were enrolled in four different courses with different language skill focuses (Table I). Each class meets once a week for two hours over an eighteen week semester. They were taught by the researcher as an instructor. All of the participants had smartphones.

TABLE I: PARTICIPANTS SAMPLE

\begin{tabular}{|c|c|c|c|c|}
\hline & Course & \multicolumn{2}{|c|}{$\begin{array}{r}\text { Number of } \\
\text { students } \\
\end{array}$} & Year level \\
\hline 1 & Business English Writing & & 30 & Junior \\
\hline 2 & English Listening and Speaking & & 53 & Junior \\
\hline 3 & $\begin{array}{l}\text { English Reading and } \\
\text { Vocabulary }\end{array}$ & & 47 & Freshman \\
\hline \multirow[t]{2}{*}{4} & $\begin{array}{l}\text { Introduction to EFL Teaching } \\
\text { Methodologies }\end{array}$ & & 54 & Sophomore \\
\hline & & Total & 184 & \\
\hline
\end{tabular}

\section{B. Course Activity Design via LINE Application}

The smartphone application, LINE, was integrated into the class agenda. Fifteen activities on the LINE interface were developed along with the curricular plan. The designed activities were aimed to offer learners more opportunities to practice the target language. They are specified as follows with the length of time indicated in parentheses:

- Learning Map (25 minutes in class): Learners are encouraged to reflect upon their previous learning experience or process and freely depict diagrams or flow charts to visually organize the information and their relationship. This is intended to raise their learning awareness in their future study. Participants first work on sheets of paper with pens. When finished, they take pictures of their work, and then post them on the LINE group.

- Word Chain (15 minutes in class): This is a word game in 
which participants come up with words that begin with the letter(s) that the previous word ended with. Words cannot be repeated in the same game. The participants compete to see how fast they can post on LINE. The person who posts the successive word the fastest gets the point and that word is also used as the next cue.

- One sentence writing (due in one week): The instructor proposes a topic and encourages learners to think about what it means to them personally. For instance, "What do families/ learning/ success/ love/ emotion mean to you?" Then, learners are given a week to contemplate the topic. Learners are then asked to make their own definition in one sentence and post it on LINE. For example, "Success means turning something I hate into something I enjoy."

- A quote (due in one week): Learners are asked to search on-line for quotations that they find inspiring. They then post the quotation and write some reflections regarding the quote.

- A joke (due in one week): Follow the same procedures as in assignment of quote).

- Metro English signs (due in one week): Learners take pictures of the watchwords or signs written in English at the Metro stations in the city. Post the pictures to the designated photo album of the LINE group. Based on the repertoire, learners study the photos and take a test after one week.

- VoiceTube clips exercise (due in one week): The instructor posts one video clip link from VoiceTube, an English learning website with diverse authentic material available. Learners view the video for one week and take a listening test afterwards in class. This exercise was offered for half of the semester on a weekly base in the English Listening and Speaking course.

- My favorite corner on campus (due in one week): Learners take pictures of one of their favorite spots on the campus. They post it and write comment in fifty words or so.

- The most important thing or person to me (due in one week): Follow the same procedures as in assignment of favorite campus corner.

- Something someone said to you that influenced you a lot (due in one week): Follow the same procedures as above.

- Q\&A: Learners respond to the instructor's question on LINE. For example, to practice how to respond to invitations in English, the instructor posted, "Would you like to have lunch with me after class?" Learners may accept or reject the invitation by texting a message. As the rules of this exercise prohibit using repetition in sentences, learners get to explore different expressions.

- Role-played conversation video making (due in one week): The learners role-play a dialogue excerpt from the textbook and videotape it. Then, they post their video clip on LINE. This exercise was offered for half of the semester on a weekly base for the English Listening and Speaking course.

- Article reading and small group discussion (due in one week): The instructor designates an article as a reading assignment. Learners form a group of four on LINE to discuss this article. This exercise was offered for half of the semester on a weekly base for the English Reading and Vocabulary course.

- Song selection and comments (due in one week): Select a song on-line and post the link to its website along with a vocabulary list and some comments on who the song is dedicated to, for instance, to yourself, a friend, parents, etc.

- Brainstorming (15 minutes in class): Instructor posts a question for the class to encourage students to think creatively. For example, in the course, Introduction to EFL Teaching Methodologies, the teacher posted, "What can you do with a BALL when teaching English to young children?"

\section{Implementation}

These courses were taught face-to-face in classroom lectures based on textbooks. One of the fifteen LINE activities was designated on a weekly basis as part of the course exercises. They were carried out according to the following procedure format:

- Illustration: The purpose, task, and requirement of each activity were explained to the learners.

- Demonstration: Each activity was then demonstrated by the instructor by giving an example.

- Time set for activity time: Some activities required learners to finish in class within the allocated time while others allowed for a longer period of time, such as one week.

- Learners at work: When the work was done, learners posted their work on the class LINE group.

- Feedback: The instructor finally checked the posted work with the class, discussed with individual learner, or asked for peer feedback in class discussion or by text on-line.

\section{Questionnaire}

In order to probe into the impact of these MALL activities, a questionnaire was given to the learners at the end of the semester. The response rate was $88 \%$. Five major questions were proposed in the survey:

Q1: Overall, do you think the class activities or assignments conducted on LINE help you learn English better? (very helpful/ somewhat helpful/ neutral/ somewhat unhelpful/ very unhelpful)

Q2: Overall, do you like the class activities or assignments conducted on LINE? (strongly like / somewhat like/ neutral/ somewhat dislike/ strongly dislike)

Q3: Among the fifteen class activities done on LINE, please specify the two most helpful or enjoyable activities for you and state your reason.

Q4: Do you feel the LINE activities offered by this course have given you enough exercise to practice in terms of your learning load? (Yes, it was enough. /There should be more. /There should be less.)

Q5: In comparison, imagine that this course offered no LINE activities. What kind of class would you prefer? (Class with LINE activities/ Class without LINE activities)

Q1 and Q2 are interested in participants' perceptions of the overall effects of the combined curriculum design, and are rated with a five-point Likert Scale. Q3 ranks the most effective or welcomed activities. Q4 and Q5 check learners' perceptions of the quantity of the MALL activities for the 
one-semester course and their preferences in regard to the curricular type. Percentage measurement is applied to the answers to Q4 and Q5.

\section{E. Interviews}

For gaining more insight, interviews were given to five participants selected at random from each class, totaling 20 interviews. The interviews were transcribed for further analysis. Patterns or categories relating to the teaching plan and learning process were identified by qualitative research methodology [12]. The inter-coder reliability is 0.87 and the intra-coder reliability 0.91 [13].

\section{RESULTS}

Quantitative results are shown in Table II. This MALL integrated course gained a positive feedback of $91 \%$ and $71 \%$ from the respondents for Q1 and Q2 respectively, in the top two categories (very helpful or somewhat helpful; strongly like or somewhat like). For Q3, the percentages showing learners' activity preference are rather averagely scattered. Specifically, participants responded that the "word chain," "joke," and "favorite campus corner" activities were the top three most helpful or welcomed activities. For Q4, more than $80 \%$ of respondents felt that the LINE activities offered gave them just enough exercises to do in terms of learning load. Likewise, for Q5, more than $80 \%$ of respondents preferred a class with LINE activities.

TABLE II: QUESTIONNAIRE RESULTS

\begin{tabular}{|l|l|}
\hline Q1 & $34 \%$ very helpful \\
& $57 \%$ somewhat helpful \\
& $6 \%$ neutral \\
& $1 \%$ somewhat unhelpful \\
& $3 \%$ very unhelpful \\
\hline Q2 & $12 \%$ strongly like \\
& $59 \%$ somewhat like \\
& $14 \%$ neutral \\
& $8 \%$ somewhat dislike \\
& $6 \%$ strongly dislike \\
\hline Q3 & $18 \%$ Word chain \\
& $15 \%$ Joke \\
& $13 \%$ Favorite campus corner \\
& $12 \%$ Metro English signs \\
& $7 \%$ Conversation video \\
& $7 \%$ Quote \\
& $6 \%$ One sentence writing \\
& $5 \%$ VoiceTube exercises \\
\hline Q4 & $83 \%$ Yes, it was enough. \\
& $5 \%$ There should be more. \\
& $13 \%$ There should be less. \\
\hline Q5 & $87 \%$ Class with LINE activities \\
& $12 \%$ Class without LINE activities \\
\hline
\end{tabular}

Qualitative data were collected from 1) the questionnaire, when comments were available, 2) interviews with the participants, and 3) the instructor's classroom notes and observations. The patterns and categories found in the data are described as follows with supporting samples.

Q1. Reasons of being helpful for learning:

- Extensive learning: "I could learn English anytime outside the classroom."

- Peer learning: "I also learn from my classmates and know what they think."

- Target language use increase: "I can use English more often every day."
- Internet resource supply: "We get to surf on the web in class and find something we don't know." "Thinking, surfing, and then posting."

- Learning on the move: "I notice what's new on our LINE group cause I check my cellphone very often."

- Learning space expansion: "The brainstorming was helpful...I got more learning space."

- Audio and visual aids: "I can live the English language...cause I get to hear or see how the language is used."

Reasons the activities were unhelpful for learning:

- Distraction: "Using a mobile phone is sometimes distracting...some of the classmates just browse for fun, not doing the assignment."

- Message flow flooding: "Sometimes, the messages are flooding the board on LINE...it's hard to find what I want."

- Learning styles: "I prefer to have printed text at hand while studying...I find it's more comfortable and less irritating when I'm off-line."

- Activity attributes: "Some assignments are better done with pen and paper...like writing an article or drawing a learning map." "If it's a test, you'd better do it on a sheet of paper...it's clearer and fairer."

Q2. Reasons for liking the activities:

- Interaction with others: "It can increase my interaction with other classmates."

- Innovative way of learning: "It's a new way of learning to me...not like other classes."

- Multi-media features: "I like to communicate not only by texts, but images, audios, and videos."

- Mobility: "It's convenient...to learn."

- Sharing: "I like to share ideas and also...use English at the same time."

- Expressing: "I feel good when I can express myself in English." "I feel more comfortable to speak up on LINE than in front of the whole class."

- Freedom of speech: "less suppression and pressure when posting my work.”

Reasons for not liking the activities:

- Technical problems: "I get upset when the connection is bad."

- Face issue: "I am afraid people will laugh at me...my poor English...bad personal image."

Q3. Reasons for favoring particular smartphone-based class activities:

- Word chain: "It's fun...exciting....and I learn more vocabulary." "It's like a game...everybody is competing for speed and points."

- Joke: "Cause some of the jokes are really funny."

- Favorite campus corner: "It feels creative...like submitting a piece of work to a newspaper as the photographers and journalists do."

- Metro English signs: "I didn't pay attention to that before...now I pay more attention to those English words around me." "It's practical."

- Conversation video: "I found it's a very effective way...to improve English speaking and pronunciation."

- Quote: "I get to know a lot of good sentences from others." "The quotes are beautiful...useful." 
- One sentence writing: "Before I put it down into one sentence, I think a while for what it really means to me...Families mean they always give me a second chance."

- VoiceTube exercises: "It's a good way to me so far...watching the video ...to improve listening ability."

Q4. Learning load: "One task a week on LINE is fine with me." "I feel the load is just enough. If there were more of the LINE activities, we would have stared at our cell phones all the time and have had less time with the teacher."

Q5. Type of pedagogical approach. In favor of MALL class: "It gives me the motive to find answers on-line." "Classmates seem to be more aggressive in learning." "It's new to me." "I find it interesting to learn with my cell phone." "The English language comes alive to me." "But the connection is sometimes a problem." "I can discuss things right away and search for answers soon."

In favor of traditional class: "I can be more relaxed." "It is good to talk face-to-face sometimes." "I feel it's more real."

\section{Discussions}

Based on the quantitative and qualitative feedback from the students, this type of pedagogy combining a smartphone application in a traditional EFL course is encouraged and welcomed. It has the advantages of portability, instantaneity, sense of connectivity, provoking motivation, extensive learning out of class, abundant opportunity for target language use, and most importantly, learning process sharing. Based on this study, some implications are suggested as follows:

\section{A. Phasing of MALL Activities}

The on-line learning activities may work best when they are in tune with the course tempo and the on-going learning stages. Therefore, selection and inclusion of the activities with proper timing is important. For example, the Learning Map assignment enables learners to inspect their learning retrospectively and prospectively; thus, this assignment can serve as a course starter or planner. Activities such as "word chain" work well for ice breaking or incentive purposes. And, to create an atmosphere of community for learning, the class could start by exploring the nearby physical setting and move on to some activities with more in-depth personal feeling as learners are getting more familiar with each other. In building up the class rapport, the course could first open from the "My favorite corner on campus" assignment or "Metro English signs," move on to "What would you put in two suitcases when moving abroad" topic for passage writing, and then "Who said what to you that influenced you a lot," until finally "The most important thing or person to me" for in-depth discussion. In addition, when the learning seems to get drowsy, some fresheners such as "Brainstorming activities" on-line or "One-sentence definition writing" would keep up learners' spirit. However, these are only considered as general guidelines for teaching plans. What makes the MALL class more flexible seems to be the spontaneity and authenticity reserved for activity arrangement, adjustment, and sequencing. All these elements contribute to the dynamics and fitness during the learning process.

\section{B. Progressing of the Classroom Ecology}

In a MALL classroom, it is likely that every traditional factor of education is unavoidably changed. Since the social media applications offer every participant equal stance for voicing, the instructors also shift some weight of reviewing to the peer learners. The class is thus open for more autonomous learning and exchange. Nevertheless, instructors need to be more capable of designing on-line activities for different learning stages. In a way, instructors are also activity designers, platform organizers, initiators, observers, and facilitators. As for learners, they seem to be more conscious and cautious of their language output on-line due to the public feature of mobile interface. Both instructors and learners cultivate a friendly and sharing virtual environment for every satisfying learning experience.

\section{Rethinking of Fun Learning}

It is observed that learning motivation can be sparkled when a favorable activity is offered in the class. However, what makes activities "favorable"? Interestingly, it appears that "favorable" has something to do with "favorite" from the learners' perspectives. There seems to be a strong relation between what the participants believe to be "helpful" and what they "like" as shown in the answers to Q1 and Q2. Participants tend to give positive feedback on learning when they like the activities or, vice versa. The top ranking activities such as "word chain" game and "jokes" confirm that activities with fun elements work well for learning. This correlates with Koster's [14] view on fun for on-line game design. He suggests that games are all essentially "edutainment" and a good game is, "one that teaches everything it has to offer before the player stops playing" ( $p$. 46). As far as a MALL class is concerned, an optimal class activity should certainly sustain learners' interest until the activity is over.

\section{Activating of Learning Horizon and Depth}

As one participant reflected, "The brainstorming was helpful...I got more learning space." It comes to light that some of the designed activities might also open a creative space for the learners. For example, in the course Introduction to EFL Teaching Methodologies, questions such as "What can you do with a BALL when teaching English to young children?" were proposed on LINE to ask for ideas. Quite a number of "think-outside-the-box" answers flooded the message board. Furthermore, with the task of song selection and dedication, some learners commented, "The best way for me to learn vocabulary is with songs I like. When doing the assignment, I found more songs and learn more words." "The song links from other classmates gave me more song learning." "I dedicate this song to my father...like the song goes, 'have I told you lately that I love you?' I would like to say so to him in English (:) but I dare not." Through proper design and inclusion of MALL activities, the learning effect can be maximized through peer interchange and the learning also takes root in their own life experience.

\section{E. Centering of Human Factors}

As an instructor, the researcher noticed that there were some critical moments when learners seemed to get 
considerably involved in the task. For instance, while undertaking the "My favorite corner on campus" assignment, one student who was not from Taiwan originally posted a picture of a remote corner on campus where he used to smoke alone. He wrote, "When I go there and smoke, I use my smartphone to check daily news and drink coffee in the morning. I feel like, today is a new day." He got fervent feedback from peers. After this, his learning behavior in the classroom became more active. It could be that he felt accepted and included by his fellow students. Another example is with the assignment, "Something someone said that influenced you a lot." A student posted, "Years ago, one of my best friends said to me, 'you know what, I've envied you all along. Do you know you are such a perfect girl in the world?' She sees what I don't see in myself...I remember this whenever I am down..." She later added some verbal comments in class with teary eyes and a smiling face. It was also noticeable that she got more engaged in course work afterwards. These examples lead the researcher to ponder on the ultimate possibility of technology-assisted learning. What seems essential is not the external advancement of the learning media or the outcome of learning, but the internal transformation of learners that evolves from the process and results in these significant improvements. Conceivably, what underpins a successful learning experience is less likely about what learners do or what they learn with the smartphone exercises, but more about being recognized, appreciated, and valued wherever their voice gets heard and their words are seen by other people.

\section{F. Internalizing of the Learning Process}

The further and, perhaps, eternal questions to explore seem to be: With speedy technology at hand, how can we make learning more humanly internalized? What are the more dominant elements and the more valuable essence in upcoming mobile class design? These issues may be investigated in future studies.

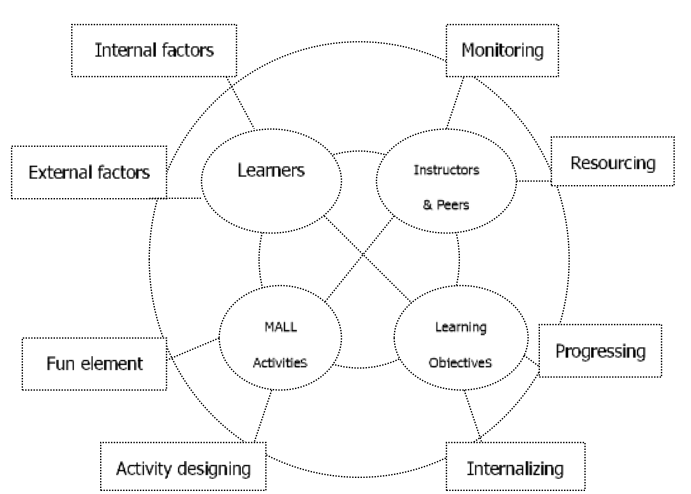

Fig. 1. The interaction model for course activity design via a smartphone application (Source: original).

\section{CONCLUSION}

Based on this study and its implications, the interaction among some MALL factors can be considered as the radial model shown in Fig. 1. The figure is simulated based on the MALL course conducted in this research.

\section{REFERENCES}

[1] C. Chen, Y. Chang, Y. Chien, C. Tijus, and C. Chang, "Incorporating a smart classroom 2.0 speech-driven PowerPoint system (SDPPT) into university teaching," Smart Learning Environment, vol. 2, no. 7, pp. 1-11, 2015.

[2] S. H. Jin, "Implementation of smartphone-based blended learning in an EFL undergraduate grammar course," Multimedia-Assisted Language Learning, vol. 17, no. 4, pp. 11-37, 2014.

[3] C. Keyes, R. H. Shroff, and E. Chow, "Pedagogical foundations of a mobile application for language acquisition," Ubiquitous Learning: An International Journal, vol. 9, no. 2, pp. 1-11, 2016.

[4] P. Liao and C. S. Lin, "Innovation design: integrating mobile-mediated communication with computational intelligence for task-based EFL learning in Taiwanese higher education," in Proc. 2016 Eighth International Conference on Advanced Computational Intelligence (ICACI), 2016, pp. 186-192.

[5] S. McCarty, T. Sato, and H. Obari, "Tokyo University of agriculture and technology case study: Smartphone App LINE for EFL peer learning," Implementing Mobile Language Learning Technologies in Japan, Singapore: Springer, 2017, pp. 33-56.

[6] A. I. Moreno, A. Vermeulen, "Profiling a MALL App for English oral practice: A case study," Journal of Universal Computer Science, vol. 21, no.10, pp. 1339-1361, 2015.

[7] S. C. Neto, "Combining distance and traditional learning: A study of the use of virtual learning environment objects and massive online open courses in statistics class," International Journal of Information and Education Technology, vol. 7, no. 1, pp. 1-6, 2017.

[8] T. Sukhbaatar, K. H. Shih, and S. H. Lan, "Observing college students' attitude towards mobile in-app usage for business communication learning," International Journal of Performance Measurement, vol. 5, no. 2, pp. 45-65, 2016.

[9] W. Bogart and S. Wichadee, "Exploring students' intention to use LINE for academic purposes based on technology acceptance model," International Review of Research in Open and Distributed Learning, vol. 16, no. 3, pp. 65-85, 2015.

[10] S. W. Yeh and T. Y. Wu, "Applying mobile annotation APPs in EFL reading: Students' perceptions and experiences," in Proc. EdMedia: World Conference on Educational Media and Technology, pp. 1546-1550, vol. 2015, no. 1, 2015.

[11] A. Zuraina, M. A. Izuddin, and M. Ghazali, "Learning technical vocabulary through a mobile App: English language teachers' perspectives," International Journal of Language Education and Applied Linguistics (IJLEAL), vol. 4, pp. 81-91, 2016.

[12] H. W. Seliger and E. Shohamy, Second Language Research Methods, Oxford, U.K.: Oxford University Press, 1989.

[13] H. E. A. Tinsley and D. J. Weiss, "Interrater reliability and agreement," Handbook of Applied Multivariate Statistics and Mathematical Modeling, San Diego, CA: Academic Press, 2000, pp. 95-124.

[14] R. Koster, A Theory of Fun for Game Design, $2^{\text {nd }}$ ed. Sebastopol, CA: O'Reilly Media, 2014, p. 46.

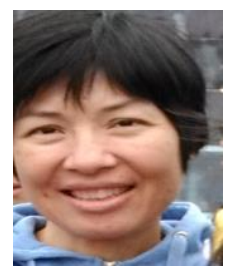

Yiching Chen was born in Taiwan and got her EdM from Graduate School of Education, Harvard University, USA. She currently teaches in the Department of Applied Foreign Languages at Takming University of Science and Technology in Taiwan. Her research interests include pedagogy and acquisition for second/foreign languages and the use of social networks in language teaching. 